\title{
Uma sequência educacional para o ensino de medida de comprimento didática como produto
}

\author{
A didactic sequence as an educational product for the teaching of length \\ measurement
}

\author{
Nazaré do Socorro Moraes da Silva ${ }^{1}$ \\ José Messildo Viana Nunes²
}

\section{Resumo}

Neste trabalho, apresentamos a descrição de um produto educacional organizado nas seções: produto educacional; a relação da pesquisa de mestrado e produto; a relevância deste e seu potencial. O produto é fruto da pesquisa de mestrado profissional desenvolvido no programa de pós-graduação em docência em educação em ciências e matemática. Ele se configura em uma sequência didática com propósito de favorecer a noção de conceitos referentes a grandeza e medida, em particular, medida de comprimento. A sequência está constituída de oito atividades em que abordamos o ensino da medida de comprimento a partir de sua grandeza, organizada na perspectiva da Teoria das Situações Didáticas. Esta sequência foi experimentada numa turma do $6^{\circ}$ ano do ensino fundamental e a partir de sua validação ampliamos seu alcance para ser trabalhada com alunos do ensino fundamental com as devidas adaptações em relação ao nível escolar da turma.

Palavras-chave: Educação matemática. Produto educacional. Teoria das situações didáticas. Grandeza comprimento. Medida de comprimento.

\begin{abstract}
In this work, we present the description of an educational product organized in the sections: educational product; the relation of the research of master's degree and product; the relevance of this and its potential. The product is the result of the research of professional master's degree developed in the program of post-graduation in teaching in education in sciences and mathematics. It is configured in a didactic sequence with the purpose of favoring the notion of concepts referring to quantity and measure, in particular, measure of length. The sequence consists of eight activities in which we approach the teaching of length measurement from its quantity, organized from the perspective of the Theory of Didactic Situations. This sequence was tested in a class of the 6th year of elementary school and from its validation we broadened its scope to be worked with elementary students with the appropriate adaptations in relation to the school level of the class.
\end{abstract}

\footnotetext{
${ }^{1}$ Mestra em Docência em Educação em Ciências e Matemáticas (UFPA), professora da Educação Básica, Secretaria do Estado de Educação do Pará, e-mail: nazaresocorro@hotmail.com 2 Doutor em Educação Matemática (PUC-SP), professor da Universidade Federal do Pará, e-mail: messildo@ufpa.br
} 
Keywords: Mathematics education. Educational product. Theory of didactic situations. Lengthquantity. Measure of length.

\section{Introdução}

Este trabalho apresenta a descrição de um produto educacional que é fruto da pesquisa de dissertação intitulada - Medida de Comprimento: uma sequência didática na perspectiva da grandeza e da medida (do Programa de PósGraduação em Docência em Educação em Ciências e Matemáticas), com intuito de legitimar uma sequência didática que favorecesse o ensino de medida de comprimento a partir da noção de grandeza e medida(SILVA, 2017).

A problemática sobre o tema grandeza e medida foi anunciada e enfrentada por Moura (1995), Rodrigues (2007), Backendorf (2010), Silva, C. (2011), Abbondati (2013), dentre outros, ao abordarem o comprimento com enfoque na medida por meio da comparação com ação de medir, explorando as diferentes unidades de medida expressas por números reais positivos, com auxílio de contexto histórico e de práticas não convencionais para medir.

Essa problemática tomou maior dimensão no campo da Educação Matemática com os trabalhos de Brito (2003), de Teixeira (2004), de Barbosa (2007) e de José da Silva (2011) ao abordarem o comprimento na perspectiva da grandeza por meio da comparação sem ação de medir (sem uso de número), estabelecendo a relação de maior, menor ou igual. Nessa revisão de estudos percebemos duas discussões acercado objeto de estudo. A primeira, enfatizando o comprimento enquanto grandeza e a segunda, evidenciando o comprimento como medida.

Com base nos estudos da literatura percebemos que essa problemática alcança vários níveis de ensino desde os anos iniciais do ensino fundamental, principalmente em relação a medida, unidade e medida de comprimento e as transformações de unidades. As pesquisas supracitadas apontam as dificuldades que tem origem em práticas de ensino que priorizam a noção de medir a instrumento de medida, e ao tamanho do objeto, tal abordagem acarreta, por 
exemplo, que o aluno assuma a transformação de unidade como algo mecânico e memorialístico, sem sentido, ou seja, sem conhecer a razão de ser de se estudar medida e grandeza.

Outro ponto importante, refere-se ao comprimento enquanto grandeza, fato pouco explorado em sala de aula, pois ao iniciarmos grandezas e medidas, falamos geralmente das diferentes grandezas, mas não tratamos a noção de grandeza, passamos diretamente para medida da grandeza. Essa situação é apontada nos estudos de Silva, J.(2011) ao analisar livros didáticos, o autor verificou que as tarefas preponderantes no livro se remetem a medir comprimento, a converter uma unidade de comprimento em outra unidade de comprimento.

Desse modo, buscamos tratar nessa pesquisa a noção de medida de comprimento e de sua abordagem em sala de aula. Na busca de uma ferramenta metodológica que nos favoreça o estudo aqui proposto, com base na engenharia de didática postulada por Michele Artigue (1996).

Essa metodologia é constituída por quatro fases: a primeira, as análises previas - que nos permitiu uma investigação aprofundada acerca do tema em questão; a segunda, concepções e análise a priori -nesta fase construímos a sequência didática com base no estudo realizado na primeira fase; a terceira, experimentação -refere-se a parte prática da pesquisa, ou seja, a aplicação da sequência didática, e quarta, a análise a posteriori e validação - esta corresponde a última fase na qual analisamos os dados produzidos pelos alunos durante o desenvolvimento da sequência, bem como o confronto das análises a priori e a posteriori, ou seja, confrontamos o que estava previstos para cada atividade e o que realmente foi atingido, a validar ou não a sequência.

Conforme as produções, os registros e os discursos observados durante 0 experimento constatamos que a sequência didática pode favorecer o ensino de medida de comprimento a partir de sua grandeza. A validação desta sequência nos levou a materialização do produto educacional denominado sequência didática para o ensino de medida de comprimento. 
O artigo está organizado nas seguintes seções: produto educacional; detalhamento do produto; e a relevância deste produto e seu potencial.

\section{Produto educacional}

O produto consiste em uma Sequência Didática que foi desenvolvida com 25 alunos 6ำ ano do Ensino Fundamental, numa escola pública na região metropolitana de Belém do Pará, com o intuito de favorecer o aprendizado de conceitos referentes a grandeza e medida, em particular, medida de comprimento. A partir dessa aplicação chegamos ao resultado que a sequência didática possibilitou a turma: a percepção da noção de comprimento como grandeza; a importância e a necessidade de quantificar essa grandeza a partir da escolha de uma unidade de medida, seja padronizada ou não padronizada; momentos de discussão, de reflexão e de tomada de decisão por meio da troca de informação entre seus parceiros de grupos e com colegas de outros grupos.

A partir da validação desta sequência constatamos que propor atividades associando a história da matemática com a articulação de três quadros ${ }^{3}$ referentes a noção de comprimento pode favorecer o ensino de medida de comprimento, bem como, a noção de grandeza, de medir, de medida, de conversão de unidades de medida, e de constituição do sistema métrico decimal. Isso nos levoua concretização deste produto educacional intitulado Sequência Didática para o Ensino de Medida de Comprimento, trabalhada com alunos do Ensino Fundamental.

Para construir esse produto nos apoiamos em alguns referenciais para tratar a noção medida de comprimento a partir de sua grandeza, como o modelo didático de Douady e Perrin-Glorian (1989), Brito (2003), Caraça (1951) entre outros. Quanto a concepção e desenvolvimento da sequência didática nos ancoramos na Teoria das Situações Didáticas defendida por Brousseau (1986, 2008).

${ }^{3}$ Douady (1993) apud Almouloud (2007, p.64) -caracteriza o quadro como sendo constituído de ferramentas de uma parte matemática, de relação entre os objetos, de formulações eventualmente diferentes e de imagens mentais associados a essas ferramentas e relações. Dois quadros podem ter os mesmos objetos e ser diferentes por causa das imagens e da problemática desenvolvida. 
A sequência didática aborda a noção de comprimento permeando os domínios da grandeza e da medida, conforme as características atribuídas ao comprimento, organizados em três quadros: o geométrico, o da grandeza e o numérico (Quadro 1).

\begin{tabular}{|c|c|c|}
\hline Geométrico & Grandeza & Numérico \\
\hline $\begin{array}{l}\text { Objetos geométricos que } \\
\text { se remetem ao } \\
\text { comprimento - linhas } \\
\text { abertas poligonais, não } \\
\text { poligonais e segmento de } \\
\text { reta. }\end{array}$ & $\begin{array}{l}\text { Comprimento } \\
\text { propriedade do objeto - } \\
\text { Classe de equivalência, } \\
\text { relação de ordem e } \\
\text { grandezas particulares ao } \\
\text { comprimento, como } \\
\text { distância, perímetro e } \\
\text { largura. }\end{array}$ & $\begin{array}{l}\text { Medidas de comprimento } \\
\text { usando diferentes } \\
\text { unidades: } \\
\text { Quantificação da grandeza } \\
\text { comprimento - atribuir um } \\
\text { número real positivo a esta } \\
\text { grandeza }\end{array}$ \\
\hline
\end{tabular}

Quadro 1- Síntese dos aspectos de comprimento atribuído aos três quadros

Fonte: Elaborado pelos Autores (2016)

Para concepção desses quadros geométrico, grandeza e numérico nos inspiramos no modelo didático sobre área proposto por Douady e Perrin-Glorian $(1989)^{4}$ e adaptamos o modelo de Brito (2003) referente a construção do conceito de comprimento como grandeza. Vale ressaltar que Brito, por sua vez, também se inspirou nessas pesquisadoras, adaptando 0 modelo das autoras ao comprimento, explorando apenas o quadro geométrico e o da grandeza.

Brito (2003) atribuiu ao quadro geométrico as linhas abertas ou fechadas, enquanto que em nossa pesquisa caracterizamos esse quadro com os seguintes objetos geométricos: linhas abertas poligonais, não poligonais e segmento de reta.

Em relação ao quadro da grandeza caracterizamos o comprimento como propriedade do objeto, em que se realiza a comparação de comprimentos de objetos sem ação de medir (sem usar número), estabelecendo a relação de maior, menor ou igual (relação de ordem); bem como, comparação entre comprimentos de objetos que possuem linhas diferentes, evidenciando que

\footnotetext{
${ }^{4}$ Douady e Perrin-Glorian (1989) propuseram um modelo didático para a construção do conceito de área por meio da distinção e articulação entre os quadros: geométrico, constituído pelas superfícies planas; das grandezas constituído pela noção de área, está caracterizada pelas classes equivalentes de superfícies de mesma área, e por fim o quadro numérico, este refere-se as medidas da área de superfície, correspondente ao conjunto dos números reais positivos.
} 
podepossuir a mesma quantidade de comprimento (classes de equivalência). Atribuímos também a este quadro a distância como caso particular da grandeza comprimento, pois segundo Barbosa (1997) a distância é o comprimento do segmento determinado por dois pontos.

O quadro numérico é constituído pelas medidas de comprimento, elegendo diferentes unidade seja não padronizada ou padronizada, expressas por números reais positivos para representar a medida da grandeza. Esse quadro evidencia a quantificação da grandeza comprimento.

Para abordar a passagem do quadro da grandeza para o numérico tomamos como referência o estudo de Caraça (1951), ao discorrer que comparar estabelecendo a relação de maior que, ou menor que é relevante, mas não é o suficiente, pois tem situações que envolvem o contexto social em que é necessário saber quanto é maior ou quanto é menor. Para isto, precisa medir, elegendo um termo de comparação único de grandeza de mesma espécie para quantificar a grandeza a ser medida, e assim, obter um resultado. Tratamos neste quadro, a noção de comprimento defendida por Lebesgue (1935), citado por Palaro (2006), por meio da comparação de segmentos que nos leva a inferir a ideia de subdivisão das unidades de medida.

Com base nas características atribuídas ao comprimento, evidenciamos na sequência didática a noção de comprimento como grandeza por meio da passagem do quadro geométrico ao quadro da grandeza, explorando a comparação de caminhos com linhas retas e curvas, estabelecendo a relação de ordem ou de equivalência. Quanto a noção de medida de comprimento, exploramos a passagem dos quadros da grandeza para o numérico por meio da escolha de uma unidade de medida mencionado no parágrafo anterior.

Para auxiliar na abordagem desses quadros, organizamos a sequência didática ancorados na teoria das Situações Didática (TSD), em especial, situação de ensino. Essa teoria foi desenvolvida por Guy Brousseau para modelar o processo de ensino e aprendizagem dos conceitos matemáticos, criando um modelo de interação entre o aluno, o saber e o milieu (meio). Sobretudo, em que 
a aprendizagem possa se desenvolver, pois para ele, "o aluno aprende se adaptando ao milieu que é um fator de contradição, de dificuldade, de desiquilíbrio, um pouco como fez a sociedade humana" (ALMOULOUD, 2007, p. $32)$.

Para esse processo, Brousseau (1986) procurou desenvolver situações de ensino que valorizassem tanto o conhecimento prévio do aluno e seu envolvimento na construção do conhecimento matemático como o trabalho do professor, ao criar condições necessárias para que o aluno se aproprie de tal conhecimento. Essa situação denominada de situação didática é o objeto central das teorias das situações, na qual corresponde ao conjunto de relações estabelecidas explicita ou implicitamente entre o aluno ou grupo de alunos, o professor e um determinado milieu, para que o aluno adquira um conhecimento constituído ou em constituição(ALMOULOUD, 2007).

Esse processo ocorre perante um "jogo hipotético" que expressa um sistema condições necessárias mínimas para o conhecimento definido, em que pode ocorrer pelas decisões para efeitos observáveis de uma atuação em um meio regido de regras, estabelecidas explicitamente ou implicitamente entre professor, aluno e conteúdo em jogo, chamado de contrato didático. Este contrato regula as intenções do professor e do aluno perante a situação didática em que os envolvidos assumem responsabilidades recíprocas, o professor com o papel de promover situações de ensino que favoreça ao aluno aprendizagem do conteúdo em jogo e o aluno procura resolver o problema proposto em que a solução se refere a apropriação desse conhecimento.

Segundo Almouloud (2007), a situação didática tem como parte essencial a situação adidática em que a intenção de ensinar não é revelada ao aluno, mas foi pensada e construída pelo professor com intuito de proporcionar ao aluno condições que o leve a aquisição do novo saber que se deseja ensinar.

As situações adidáticas são construídas com fins didáticos, ou seja, com intenção de ensino, embora sejam situações que aparentam sem intencionalidade 
didática, as quais o professor apresenta um problema para o aluno de modo que este possa resolvê-lo sem necessariamente a intervenção do seu mestre.

A situação didática ocorre a partir do momento que o professor propõe 0 problema ao aluno para que ele resolva, tomando para si parte da responsabilidade pela aprendizagem, denominado de devolução, que por sua vez, deve ter a intenção de provocar uma interação suficientemente rica e que permita ao aluno o desenvolvimento autônomo. Essa situação didática conclui-se com a institucionalização, em que o professor dá estatuto ao conhecimento produzido pelo aluno. Agora, se o aluno aceitar tal desafio e obter sucesso, inicia-se o processo de aprendizagem.

Brousseau (2008) analisa esse processo em quatro tipos situações: ação, formulação, validação e institucionalização.

Situação de ação: exige que o conhecimento do aluno se manifeste por decisões e ações adequadas e eficazes sobre o meio, sem a necessidade de expressá-las por meio de um discurso, nem explicar esse conhecimento.

Situação de formulação: nesta situação o aluno precisa expressar sua tomada de decisão, ou seja, comunicar uma informação matemática, justificando sua solução com base em aspectos teóricos.

Situação de validação: nesta situação o aluno precisa provar o seu conhecimento formulado por meio de debates e discussões, confrontando opiniões e procurando entrar em acordo, utilizando argumentos, teoremas que possam validar o seu conhecimento.

Situação deinstitucionalização: esta situação se remete ao professor, o qual dará estatuto aos conhecimentos validados pelos alunos, com intuito de situar um caráter universal, articulando com outros conhecimentos. Tornando assim, o conhecimento novo produzido pelos alunos socialmente aceito.

Essas situações de ação, formulação e validação se caracterizam como adidáticas por fazerem parte de momentos que possibilitam a construção do conhecimento por parte do aluno, ou seja, o controle sobre produção do conhecimento está nas mãos do aluno e, por sua vez, o professor tem o controle 
somente do andamento da situação. Enquanto, a Institucionalização é uma situação de natureza didática, em que o professor tem o controle do conhecimento produzido pelo aluno, reforçando e generalizando, dando-lhe um estatuto, numa passagem desse conhecimento em jogo para uma dimensão histórica e cultural do saber científico. Vale salientar, para que esse processo ocorra é fundamental um milieu organizado e planejado pelo professor, além do contrato didático para gerir todo esse processo.

Nesse sentido, procuramos explorar as atividades que constituem a sequência didática a partir do modelo de situação de ensino defendido por Brousseau (2008), iniciando com devolução e perpassando as situações de ação, formulação, validação e institucionalização.

A partir desses referenciais, elaboramos atividades com situações problemas, comportando três situações ${ }^{5}$ : histórico-epistemológica, de comparação e de medida.

- Situação histórico-epistemológica: remete-se ao contexto histórico que versa na abordagem da origem e na evolução das grandezas e medidas, em particular, o comprimento. Nesta situação é relevante evidenciar as primeiras ações em relação ao ato de medir, a necessidade de medir, os instrumentos de medida utilizados pelos povos antigos e a necessidade de uma padronização universal de medida.

- Situação de comparação: refere-se as situações que explorem comparação de comprimentos sem ação de medir (sem uso de número) com atividades que proporcione ao aluno realizar comparação por meio da visualização ou com auxílio de objetos como referência, por exemplo, o barbante para verificar se um comprimento de um determinado objeto ou percurso é maior, menor ou igual ao outro. Esta situação evidencia o comprimento no domínio da grandeza.

\footnotetext{
${ }^{5}$ Esta situação se remete ao tipo de atividades e não ao sentido da situação de ensino e seus momentos que Brousseau faz referência.
} 
- Situação de medida: remete-se as situações que explorem a quantificação da grandeza na qual se atribui um valor numérico a esta grandeza. Esta situação evidencia o comprimento no domínio da medida com atividades que abordam a necessidade de medir e como medir, passando da grandeza (comprimento) para medida dessa grandeza, elegendo unidades de medida não padronizada, padronizada para se chegar até a constituição do sistema métrico decimal e conversão de unidades de medida.

Essas situações nos permitiram desenhar um modelo de abordagem de grandeza e medida, em particular, de comprimento que poderá direcionar 0 professor a organizar sua própria sequência no sentido de elaborar ou eleger suas atividades sobre este tema conforme mostra o Quadro 3:

\begin{tabular}{|c|c|}
\hline Abordagem & Proposições \\
\hline Contexto histórico & $\begin{array}{l}\text { Trabalhar atividades que explorem a origem e evolução } \\
\text { do conteúdo em jogo (medida de comprimento). }\end{array}$ \\
\hline $\begin{array}{l}\text { Noção da grandeza que se } \\
\text { pretende medir } \\
\text { (comprimento) }\end{array}$ & $\begin{array}{l}\text { Trabalhar atividades que explorem a comparação sem } \\
\text { ação de medir, estabelecendo a relação de maior, menor } \\
\text { ou igual entre objetos ou coisas (Preferencialmente } \\
\text { objetos que façam parte do cotidiano do aluno). }\end{array}$ \\
\hline $\begin{array}{c}\text { Noção de medida de } \\
\text { comprimento(quantificação } \\
\text { da grandeza) }\end{array}$ & $\begin{array}{l}\text { Trabalhar atividades que evidenciem a relevância da } \\
\text { quantificação da grandeza (medida), propondo situações } \\
\text { que levem o aluno a eleger uma unidade. Utilizando } \\
\text { unidades não padronizadas (informais), padronizadas não } \\
\text { oficiais }{ }^{6} \text { e padronizadas oficiais. } \\
\text { - Explorar atividades envolvendo ação de medir com } \\
\text { uso das partes do próprio corpo e, também, objetos } \\
\text { concretos como palito de picolé, canudo, entre outros; } \\
\text { - Propor a construção de um instrumento de medida } \\
\text { padrão correspondente a } 1 \text { metro de comprimento } \\
\text { sem ser graduado; } \\
\text { - Abordar atividades que evidenciem a necessidade de } \\
\text { subdivisão de unidade, explorando outros conteúdos } \\
\text { da matemática como fração, multiplicação e divisão } \\
\text { (submúltiplos do metro); } \\
\text { - Trabalhar atividades que explorem mensuração de } \\
\text { longa distância para evidenciar unidades superiores }\end{array}$ \\
\hline
\end{tabular}

${ }^{6}$ Padrões não oficiais - são os objetos da caixa de ferramenta que adotamos como unidades de medida padrões utilizados pela turma, como o canudo de plástico entre outros, mas que não são oficiais, como as unidades de medidas do Sistema Métrico Decimal. 
ao metro (múltiplos do metro).

Quadro 3 - Síntese da abordagem das atividades

Fonte: Elaborado pelos Autores (2017)

\section{Detalhamento do produto educacional}

Com base nos referenciais mencionados anteriormente, a sequência didática foi constituída de oito atividades com abordagem prevista no Quadro 3, exposto na seção anterior. Cada atividade é composta respectivamente de título, objetivos, procedimentos, materiais e uma breve orientação para professor.

Título: direcionado o que se pretende abordar na atividade.

Objetivos: refere-se o que se deseja realizar e alcançar.

Material: relação dos materiais necessários para auxiliar no desenvolvimento das atividades. Alguns fundamentais para abordagem e compreensão das noções de conceitos referentes a grandezas e medidas, como: grandeza comprimento, medir, medida de comprimento, unidade, conversão de unidades e constituição do sistema métrico decimal.

Procedimentos: orientam o desenvolvimento da atividade ao que se refere a organização da turma em grupos, bem como, apresentar as atividades e o andamento para resolução dos problemas propostos, além de nortear a utilização dos materiais. Vale ressaltar que a orientação a respeito do uso do material não se refere as estratégias adotas pelos grupos, pois estas serão particularidades de cada grupo.

Orientações ao professor: são relevantes para que o professor possa obter informações importante para realização da atividade em relação do que se espera do comportamento dos alunos diante das atividades, uma vez que, esta sequência foi experimentada numa turma de $6^{\circ}$ ano do ensino fundamental. Além de sugestões para o desenvolvimento das atividades a partir do que foi observado na aplicação da sequência durante a pesquisa.

Entre os materiais, destacamos como fundamentais:

- Folha de atividade com os problemas propostos; 
- Um texto com recortes de aspectos histórico inerente a pesos e medidas, evidenciando as primeiras ações em relação ao ato de medir, a necessidade de medir, os instrumentos de medida utilizados pelos povos antigos e a necessidade de uma padronização universal de medida;

- Uma caixa de ferramenta (Figura 1) contendo diversos materiais escolares: borracha branca, canetas hidrográficas de cores diferentes, lápis grafite e tesoura escolar, além de outros objetos para servirem de medianeiros ${ }^{7}$ : "régua" feita de papel cartão de 10 centímetros $(\mathrm{cm})$ sem graduação, clipes, canudo de plástico, palito de picolé, barrinhas de madeira de $3 \mathrm{~cm}$ (sem graduação), barbante, linha de crochê,tiras de papel quarenta quilos denominada tira padrão com dimensão de 1 metro de comprimento sem graduação, justamente para que os grupos possam graduar no decorrer de uma das atividades e instrumentos de medida oficiais, como: réguas (30 $\mathrm{cm})$, fitas métricas $(150 \mathrm{~cm})$ e trenas (5 metros);

Figura 1- Caixa de ferramenta

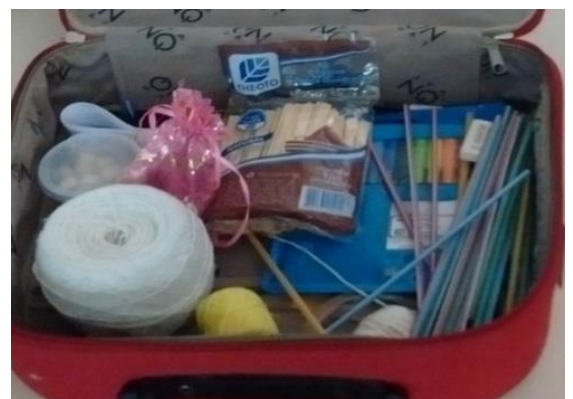

Fonte: Autores (2016)

- As barras de madeiras da escala de cuisenaire ${ }^{8}$ e os blocos do material dourado (somente os cubos soltos) são de fundamental

\footnotetext{
7 Medianeiros: caracterizados por Brito (2003) como instrumentos da caixa de ferramenta que servem para mediar comparações que não podem ser feitas diretamente.

8 Conforme Boldrin (2009) - Escala de cuisenaire é um material concreto constituído por uma series de barras de madeira sem divisão em unidades e com tamanhos variando de uma a dez unidades. Cada tamanho corresponde uma cor.
} 
importância para constituição da unidade padrão de comprimento, o metro, conforme mostra a Figura 2:

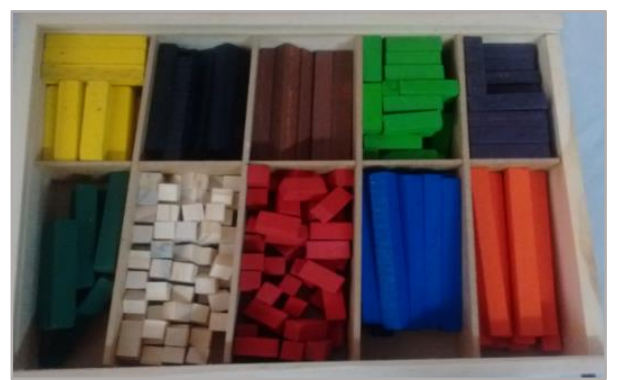

Figura 2- Escala de cuisenaire

Fonte: Autores (2016)

A respeitos desses materiais salientamos que, embora, a barrinha de madeira e bloco do material dourado apresentem forma de sólidos geométricos, apenas faremos uso do comprimento da aresta de cada objeto. O cubo com aresta de 1centímetro $(\mathrm{cm})$ de comprimento e a aresta de maior comprimento da barra de madeira sobreposta na posição horizontal com dimensão de 1 a $10 \mathrm{~cm}$. Haja vista que todas arestas do bloco de madeira de forma cúbica possuem a mesma medida, por isso acreditamos que esse objeto não provocará obstáculo didático $^{9}$ ao aluno. Apresentamos no Quadro 2 uma síntese da sequência didática:

\begin{tabular}{|c|c|c|c|}
\hline Abordagem & Atividades & Objetivos & Material \\
\hline $\begin{array}{l}\text { Contexto } \\
\text { histórico }\end{array}$ & $\begin{array}{l}\text { 1- Os primeiros } \\
\text { passos para medir }\end{array}$ & $\begin{array}{l}\text { Ler, interpretar e discutir } \\
\text { sobre o texto; destacar } \\
\text { palavras e excerto do texto. }\end{array}$ & $\begin{array}{lr}\text { Texto } & \text { e } \\
\text { dicionário } & \text { de } \\
\text { português. } & \end{array}$ \\
\hline $\begin{array}{l}\text { Comprimento } \\
\text { como } \\
\text { grandeza }\end{array}$ & $\begin{array}{l}2 \text { - Comparação de } \\
\text { caminhos }\end{array}$ & $\begin{array}{l}\text { Realizar comparação de } \\
\text { comprimentos sem ação de } \\
\text { medir. }\end{array}$ & $\begin{array}{ll}\text { Folha } & \text { de } \\
\text { atividade, } & \\
\text { caixa } & \text { de } \\
\text { ferramenta. } & \end{array}$ \\
\hline $\begin{array}{l}\text { Quantificação } \\
\text { da grandeza } \\
\text { (medida de } \\
\text { comprimento) }\end{array}$ & $\begin{array}{l}3 \text { - Amedida da } \\
\text { altura dos alunos }\end{array}$ & $\begin{array}{l}\text { Construir da noção de } \\
\text { medida, } \\
\text { unidades } \\
\text { padronizadase } \\
\text { padronizadas não oficiais. }\end{array}$ & $\begin{array}{l}\text { Folha de } \\
\text { atividade, caixa } \\
\text { de ferramenta e } \\
\text { medidas } \\
\text { antropométricas. }\end{array}$ \\
\hline
\end{tabular}

9 Conforme Almouloud (2007) apoiado em Brousseau (1986) - Obstáculo didático são os "obstáculos que surgem a partir das escolhas feitas no processo de ensino e provocadas por uma transposição didática que o professor dificilmente poderá renegociar no momento restrito de sala de aula". 


\begin{tabular}{|c|c|c|}
\hline $\begin{array}{l}4 \text { - Objetos de sala } \\
\text { de aula e partes do } \\
\text { corpo como meio } \\
\text { para medir }\end{array}$ & $\begin{array}{l}\text { Medir objetos de sala de } \\
\text { aula, utilizando como } \\
\text { unidade objetos da caixa de } \\
\text { ferramenta; associar a } \\
\text { grandeza comprimento com } \\
\text { partes do corpo. }\end{array}$ & $\begin{array}{l}\text { Folha de } \\
\text { atividade, caixa } \\
\text { de ferramenta e } \\
\text { medidas } \\
\text { antropométricas. }\end{array}$ \\
\hline $\begin{array}{l}5 \quad-\quad \text { A } r \text { medida } \\
\text { padrão - o metro e } \\
\text { seus submúltiplos. }\end{array}$ & $\begin{array}{l}\text { Construção } \text { de } \\
\text { instrumento de } \\
\text { padrão medida } \\
\text { reconhecer o instrumento } \\
\text { de medida padrão oficial; } \\
\text { construção do metro e seus } \\
\text { submúltiplos. }\end{array}$ & $\begin{array}{lr}\text { Caixa } & \text { de } \\
\text { ferramenta, tira } \\
\text { padrão, barras } \\
\text { da escala de } \\
\text { cuisenaire, fita } \\
\text { métrica, régua } \\
\text { graduada } \\
\text { trena. }\end{array}$ \\
\hline $\begin{array}{lll}6 & -A & \text { distância } \\
\text { entre os } & \text { espaços } \\
\text { da escola }\end{array}$ & $\begin{array}{l}\text { Compreender } \\
\text { necessidade de unidades } \\
\text { medida maiores que o } \\
\text { metro; conceber os } \\
\text { múltiplos do metro. }\end{array}$ & $\begin{array}{l}\text { Folha de } \\
\text { atividade, caixa } \\
\text { de ferramenta, } \\
\text { tira padrão, } \\
\text { barras da escala } \\
\text { de cuisenaire, } \\
\text { fita métrica, } \\
\text { régua graduada } \\
\text { e trena. }\end{array}$ \\
\hline $\begin{array}{ll}7-\text { Unidades } & \text { de } \\
\text { medidas } & \\
\text { convenientes } & \text { a } \\
\text { cada situação } & \\
\end{array}$ & $\begin{array}{l}\text { Associar uma unidade de } \\
\text { medida em cada situação. }\end{array}$ & $\begin{array}{l}\text { Folha de } \\
\text { atividade }\end{array}$ \\
\hline $\begin{array}{ll}8 \text { - Conversão } & \text { de } \\
\text { unidades } & \text { de } \\
\text { medida } & \end{array}$ & $\begin{array}{l}\text { Realizar conversão entre as } \\
\text { unidades de medida de } \\
\text { comprimento; compreender } \\
\text { a relação de equivalência } \\
\text { entre as unidades de } \\
\text { medida. }\end{array}$ & $\begin{array}{l}\text { Folha } \\
\text { atividade }\end{array}$ \\
\hline
\end{tabular}

Quadro 2 - Síntese da sequência didática

Fonte: Elaborado pelos Autores (2017)

A primeira atividade faz uso da história da matemática numa perspectiva epistemológica para introduzir uma situação adidática que mostre aos alunos a evolução e os "porquês" dos conceitos matemáticos citados acima e, assim, auxiliá-los nas ações que poderão desenvolver no decorrer das demais atividades.

$\mathrm{Na}$ segunda atividade, abordamos a noção de comprimento como grandeza, evidenciando a passagem do quadro geométrico para o da grandeza por meio da comparação (sem uso de número), estabelecendo a relação de 
maior, menor ou igual entre os caminhos de linhas curvas e retas a partir de um mapa que representa o entorno da escola. Pois, com esta comparação, o aluno poderá perceber que caminhos distintos podem ter o mesmo comprimento. Para esta atividade, os alunos podem utilizar como estratégias a visualização ou/ e a sobreposição de objetos medianeiros, retirados da caixa de ferramenta para auxiliar na comparação entre os caminhos. Entre os objetos, destacamos o barbante como o mais adequado para sobreposição dos caminhos linhas curvas (SILVA, 2017).

$\mathrm{Na}$ terceira atividade, propomos um problema que evidencia "a passagem do quadro da grandeza para o numérico", envolvendo primeiramente a comparação entre as alturas de três alunos em uso de número por meio da visualização, identificando o de maior ou menor alturas em uso do número para, em seguida, perceberem a necessidade de determinar quanto é maior ou menor. Para isto, sentirem a necessidade de medir, elegendo algo para esta ação. Primeiramente, informal (não padronizadas) que recorre a própria história quando o homem tomou a si próprio como padrão de medida, utilizando partes do corpo como referência para medir as coisas (medidas antropométricas). Seguindo para uso dos objetos da caixa de ferramenta, por exemplo, palito de picolé, canudos de plásticos, entre outros (padronizadas não oficiais).

Nessa atividade, o aluno pode vivenciar um importante momento das características do comprimento, passando da grandeza para a quantificação desta (medida da grandeza) ao eleger uma unidade para medir altura, compará-la e expressar o resultado desta comparação, explorando assim, conceito relevante como medir, medida e unidade.

A quarta atividade é uma extensão da terceira por conta de levar o aluno a vivenciar ações de medir com objetos da sala de aula, utilizando as próprias partes do corpo e também os objetos da caixa de ferramenta como unidade de medida. Além de criar relações entre os objetos menores com os objetos de maior comprimento, introduzindo assim, a ideia de subdivisão de unidade ao comparar 
que uma palma pode corresponder aproximadamente quatro dedos ou que um canudo pode corresponder aproximadamente a dois palitos de picolé.

A quinta atividade se remete a construção de um instrumento de medida padrão da turma para auxiliar os alunos na a compreensão da constituição da medida padrão oficial, o metro e seus submúltiplos. Além de levar o aluno a refletir sobre as subdivisões das unidades de medidas trabalhadas, a reforçar a noção de medida, bem como, a perceber que o valor da medida de comprimento se altera de acordo com a unidade adotada para medir. A construção do instrumento se dá por meio da graduação de uma tira padrão com o auxílio da sobreposição justapostas pelas extremidades de barrinhas da escala de cuisenaire conforme a Figura 3.

Figura 3- Exemplo da graduação da tira padrão

Fonte: Autores (2016)

A sexta atividade explora um problema envolvendo o espaço escolar com mensuração de longa distância para abordar a necessidade de unidades maiores que o metro. Nesta atividade, os alunos precisam encontrar uma estratégia para medir a distância entre a sala de aula e quadra de esporte da escola. Podendo utilizar o barbante para percorrer a distância entre essas localizações e, em seguida, medir utilizando os instrumentos oficiais, como fita métrica ou trena, apresentados na atividade 5 .Em relação a sétima e a oitava atividades, ambas se remetem a resolução de problemas a partir da institucionalização dos conceitos trabalhados nas atividades anteriores como identificar as unidades mais convenientes para cada situação proposta, bem como, realizar transformações de unidades de medida de comprimento.

Para realização da sequência didática não precisa de laboratório de informática ou pedagógico, nem instrumento como Datashow, apenas os materiais explicitados anteriormente ou materiais similares que possam substituílos para mesmas funções. Quanto ao tempo de realização da sequência, estipulamos o mesmo tempo de aplicação ocorrido em nossa pesquisa no qual se 
deu em sete encontros, sendo um para o desenvolvimento de cada atividade levando em média duas aulas de 45 minutos. Com exceção das duas últimas atividades, estas foram realizada sem um único encontro.

Quanto a metodologia, as atividades podem ser realizadas em grupos de no máximo 5 componentes, no qual cada grupo pode eleger um representante para auxiliar no desenvolvimento das atividades, pois acreditamos que realizar atividades em grupo pode provocar discussões, inicialmente, entre os componentes para a tomada de decisão durante a resolução do problema proposto na atividade que favorecerá comunicação de ideias entre os grupos, compartilhando opiniões e estratégias entre os demais.

Conforme anunciado na seção anterior, o desenvolvimento da sequência tem como basilar as situações de ensino proposta por Brousseau (2008) numa organização que favoreça o aluno a ter o papel de ator principal na construção do seu conhecimento. Nesta perspectiva, o desenvolvimento de cada atividade está organizado em quatro etapas: apresentação da atividade e devidas orientações, esta etapa se remete no momento da devolução em que o professor propõem o problema para a turma, para que cada grupo tenha interesse em resolver e possa resolver; desenvolvimento da atividade corresponde a situação de ação com a tomada de decisão dos componentes de cada grupo (aspectos da ação) e a discussão acerca das estratégias adotadas pelos alunos para resolução do problema proposto (aspectos da formulação); análise do registro escrito na lousa pelos alunos de seus argumentos orais a respeito da estratégias adotada e de sua solução (aspectos da validação); e por último, a formalização dos conceitos referentes ao tema em questão pelo professor a partir das compreensões adquiridas pelos alunos durante 0 desenvolvimento da atividades (institucionalização).

Vale ressaltar que nem todas atividades apresentam a institucionalização, pois depende do objetivo da atividade como o caso da primeira. Esta busca promove discussões importantes para desdobramentos das demais atividade. Outro caso, se remete as duas últimas atividades que sua resolução se dá a partir 
da institucionalização das atividades anteriores, ou seja, aborda conhecimentos já institucionalizados.

\section{Relevância do produto e seu potencial}

Esse produto educacional possibilitará aos professores (ou futuros professores) da Educação Básica, em especial do ensino fundamental, desenvolver ações em sala de aula para abordar a noção de medida de comprimento, por conter atividades que exploram aspectos conceituais sobre grandezas e medida, em particular, medida de comprimento, permeando o seu contexto histórico-epistemológico até contexto da realidade do aluno numa abordagem em que se trata a grandeza comprimento e a necessidade de sua quantificação (medida de comprimento).

Além disso, apresenta uma organização didática que evidencia situações de ensino que favorece ao aluno o desejo em resolver problemas, despertando seu interesse em agir, refletir, conjecturar, indo em busca do conhecimento em jogo. Uma abordagem diferenciada que fomenta a tomada de decisão e a troca de informações entre os alunos na busca de uma solução para o problema proposto.

Esse produto foi experimentado numa turma do $6^{\circ}$ ano do ensino fundamental, mas pode ser trabalhado com alunos tanto dos anos iniciais como finais do Ensino Fundamental com as devidas adequações em relação ao nível escolar da turma.

\section{Considerações finais}

Este artigo se propôs apresentar a descrição de um produto educacional intitulado sequência didática para o ensino de medida de comprimento, que emergiu a partir de duas discussões: o comprimento na perspectiva "da grandeza" e "da medida" durante uma pesquisa de mestrado profissional. Essas discussões nos possibilitaram conhecimentos que circundam conceitos acerca de grandeza e medida, em particular, medida de comprimento no âmbito histórico-epistemológico e didático. 
Esses conhecimentos nos fizeram refletir sobre o modelo didático que aborda a distinção e articulação entre os quadros geométrico, da grandeza e o numérico nos oportunizando tratar a medida de comprimento a partir de sua grandeza, explorando essas discussões não de modo separado e sim, mostrando que uma depende da outra e que para o aluno compreender a medida de comprimento e as transformações de suas unidades é relevante conhecer o comprimento como grandeza. Por outro lado, pensarmos em uma organização de ensino que explorasse esses conceitos, tendo o professor como mediador do processo de ensino e aprendizagem ao organizar e planejar uma situação de ensino que valorizasse a participação do aluno como ator principal na construção de seu conhecimento.

A partir desses conhecimentos construímos uma sequência didática que foi experimentada e validado dando origem ao produto educacional como uma proposta que possa nortear e ampliar o olhar dos docentes a respeito do ensino de conteúdos matemáticos e passível de adaptação, levando em consideração a realidade da turma. Vale salientar que construir uma sequência didática que comporte os aspectos tanto conceitual como didático não é fácil, isso é fruto de muito trabalho, pois precisa dispor de elementos que possibilite tal proposta, como tempo, investigação do objeto de estudo e dos sujeitos envolvidos (alunos) e apoio da instituição, a qual o professor realiza seu trabalho docente, entre outros.

Com isso esperamos que os professores ou futuros professores da Educação Básica tanto os que ensinam matemática como os professores de matemática possam vislumbrar como uma possibilidade metodológica diferenciada para o ensino de medida de comprimento. De modo que auxilie o professor em suas práticas docentes, agregando-o a sua experiência e ao contexto do aluno para favorecer o desenvolvimento de um bom trabalho. 


\section{Referências}

ABBONDATI, M. Um ambiente virtual de aprendizagem para o ensino de Tópicos de Matematica do Ensino Fundamental. 2013. 183 f. Dissertação. ( Mestrado profissional em Ensino de Ciencias Exatas) - Centro de Ciencias Exatas e Tecnologia. Universidade Federal de São Carlos. São Carlos, 2013.

ALMOULOUD, S. A. Fundamentos da didática da matemática. $2^{\underline{a}}$ edição. Curitiba: Ed. UFPR, 2007.

ARTIGUE, M. Engenharia Didáctica. In: BRUN, Jean (org.); FIGUEIREDO, Maria José (tradução). Didáctica das matemáticas. Lisboa: instituto Piaget, 1996. P.193 - 217.

BACKENDORF, V. R. Uma sequência didática de medidas de comprimento e superficie no 5 ano do Ensino Fundamental: Um estudo de caso. 2010. 188 f. Dissertação (Mestrado profissionalizante em Ensino da Matemática) - Universidade Federal do Rio Grande do Sul, Porto Alegre, 2010.

BARBOSA, R. P.Efeitos de visualização em atividades de comparação de comprimento de linhas abertas. 2007. 318 f. Tese (Doutorado em Educação) - UFPE. Recife,2007.

BARBOSA, J. L. M. Geometria Euclidiana Plana. Fortaleza: SBM, 1997.

BOLDRIN, M. I. Barrinhas de Cuisenaire: introdução à construção dos fatos fundamentais da adição. São Paulo, 2009.

ttps://pedagogiafmu.files.wordpress.com/2010/09/barrinhas-de-cuisenaire. Acesso em 25 de agosto de 2016.

BRITO, A. F. Um estudo sobre a influência do uso de materiais manipulativos na construção do conceito de compreimento como grandeza no $2^{\circ}$ ciclo do Ensino Fundamental. 2003. 203 f. Dissertação (Mestrado em Educação) - UFPE. Recife,2003.

BROSSEAU, G.Fondements et méthodes em didactique des mathematiques.

Rechercehs em didactique des mathématiques, Grenoble, v. 7, n. 2 , p. 33 - 115, 1986.

. Introdução ao estudo da teoria das situações: conteudos e metodos de ensino.Saõ Paulo: Ática, 2008.

CARAÇA, B. J. Conceitos Fundamentais de Matemática. Lisboa: Gradiva, 1951.

DOUADY, R.; PERRIN-GLORIAN, M. J. Un Processus D'Apprentissage du Concept D'Aire de Surface Plane. Educational Studies in Mathematics, v. 20, n. 4, p. 387-424, 1989.

MOURA, A. R. L. A medida e a criança pré-escolar. 1995. 221 f. Tese (Doutorado em Educação) - Faculdade de Educação. Universidade Estadual de Campinas. Campinas, 1995. 
PALARO, L. A. A concepão de Educação Matemática de Henri Lebesgue. 2006. 340 f. Tese (Doutorado em Educação Matemática) - Pontifícia Universidade Católica de São Paulo. São Paulo, 2006.

RODRIGUES, M. S. O ensino de medidas e grandezas através de uma abordagem investigatoria. 2007. 203 f. Dissertação ( Mestrado em Ensino de Ciencias Naturais e Matemática) - UFRN. Natal, 2007

SILVA, C. C. R. Construção de conceitos de grandezas e medidas nos anos iniciais: Comprimento, massa e capacidade. 2011. 230 f. Dissertação (Mestrado em Educação) Faculdade de Educação da Universidade de Brasilia - UnB, Brasilia, 2011.

SILVA, J. V. G. Análise da abordagem de comprimento, perímetro e àrea em livros didaticos de matemática do 60 ano do Ensino Fundamental sob a ótica da Teoria Antropológica do Didático. 2011. 195 f. Dissertação ( Mestrado em Educação Matemática e Tecnologia) - UFPE. Recife, 2011.

SILVA, N. S. M. Medida de Comprimento :Uma Sequência na Perspectiva da Grandeza e Medida. 2017. 168 f. Dissertação (Mestrado Profissional em Eduação em Ciencias e matemáticas)- UFPA. Pará, 2017.

TEIXEIRA, S. G. Concepções de alunos de Pedagogia sobre os conceitos de comprimento e perímetro. 2004. f. Dissertação (Mestrado em Educação) Universidade Federal de Pernambuco. Recife, 2004. 